\title{
Clinical Outcomes of Patients over 75 Years of Age with Degenerative Spondylolisthesis Following Bilateral Decompression via Unilateral Approach
}

\author{
Mustafa Kemal ILIK ${ }^{1}$, Mustafa GOLEN², Faik ILIK ${ }^{3}$, Ilker COVEN ${ }^{4}$, Yildiray DAL ${ }^{5}$ \\ ${ }^{1}$ Farabi Hospital, Neurosurgery Clinic, Konya, Turkey \\ ${ }^{2}$ Medova Hospital, Neurosurgery Clinic, Konya, Turkey \\ ${ }^{3}$ Baskent University, Department of Neurology, Konya, Turkey \\ ${ }^{4}$ Meram Training and Research Hospital, Neurosurgery Clinic, Konya, Turkey \\ ${ }^{5}$ Konya Hospital, Anaesthesiology Clinic, Konya, Turkey
}

\section{ABSTRACT}

AIM: To investigate the clinical outcomes of bilateral decompression via unilateral approach (BDUA) on degenerative spondylolisthesis with spinal stenosis in patients over 75 years of age.

MATERIAL and METHODS: Elderly patients ( $n=41$; average age $=79.3 \pm 2.5$ years) who underwent BDUA under spinal anaesthesia between April 2011 and May 2014 were enrolled. Visual Analogue Scale (VAS) scores and Oswestry Disability Index (ODI) values of the patients were evaluated preoperatively and at the last visit postoperatively (Mean follow-up period=27 month). All parameters were analysed using Student paired-sample t test with $\mathrm{p}<0.05$ considered statistically significant.

RESULTS: All 41 patients experienced significant postoperative improvement in VAS leg $(p<0.01)$ and back pain $(p<0.05)$ scores. Average ODls were $52 \pm 4.1 \%$ preoperatively and $39 \pm 3.5 \%$ postoperatively. All changes were statistically significant.

CONCLUSION: BDUA is a safe and very effective treatment in elderly patients with degenerative spondylolisthesis with spinal stenosis. This procedure has a very low complication rate and can be performed successfully under spinal anaesthesia.

KEYWORDS: Elderly patient, Minimally Invasive Approach, Spondylolisthesis

\section{INTRODUCTION}

$\mathrm{L}$ umbar degenerative spondylolisthesis (LDS), initially described during the first half of the $20^{\text {th }}$ century, is a degenerative disease of the spine (9). Neurogenic claudication, back pain and radiculopathy caused by degenerative spondylolisthesis, is a pathology commonly observed in elderly patients. Conservative treatment is generally chosen for elderly patients due to high surgical complication rates. However, surgical intervention is recommended for patients whose symptoms persist despite conservative treatment (25).

Current surgical strategies for the treatment of LDS with stenosis (LDSS) fall into two categories: fusion and non-fusion. Although decompression with stabilisation is one treatment option, the complication rate increases as a result of comorbidities present in elderly patients in addition to surgical complications, such as blood loss, prolonged operation time, and implant failure. Minimally invasive surgical techniques result in decreased blood loss, less tissue dissection, avoidance of fusion, and earlier mobilisation (4-8,10,11,18,2022). An effective technique used to provide decompression of LDSS is bilateral decompression via a unilateral approach (BDUA) $(15-17,23,26)$. We routinely perform this procedure at our centre in elderly patients with low-grade LDSS. 
The goal of this study was to evaluate the efficacy and benefits of BDUA for LDSS in patients over 75 years. We hypothesized that this approach could be an effective alternative to fusion surgery for the treatment of elderly patients.

\section{MATERIAL and METHODS}

In this retrospective study, 41 consecutive elderly patients who underwent BDUA for low-grade LDSS were assessed. No patient had a history of previous lumbar spine surgery. Patients over 75 years of age with radiculopathy or neurogenic claudication associated with degenerative spondylolisthesis were included in our study. Anterior-posterior, dynamic X-ray, and lumbar magnetic resonance imaging (MRI) (Figure 1) were used to determine preoperative slippage and compression; a diagnosis of radiculopathy was confirmed by needle electromyography (EMG). Lumbar MRI was used to determine the slippage and adequacy of decompression at the last visit after surgery (Figure 2). The Visual Analogue Scale for leg pain (VAS-L) and for back pain (VAS-B) and Oswestry Disability Index (ODI) tests were administered to each patient $(1,14)$. Information regarding the patients' co-morbidities, as well as intraoperative and postoperative complications, was also evaluated in this series.

\section{Surgical Procedure}

Between April 2011 and May 2014, the same senior author (MKI) performed surgeries employing the BDUA method in all patients, as described previously (13). All patients underwent spinal anaesthesia; while lying in the prone position, a 3-5 $\mathrm{cm}$ midline skin incision was made overlying the target level for spinal decompression. Surgery was performed on the side of the patient with the worse leg pain. After the linear fascial incision, the paraspinal muscles were dissected. The spinous process, lamina, and interlaminar space were exposed. A Taylor retractor was used. The ipsilateral cephalad and caudal lamina were resected using Kerrison rongeurs and a high-speed burr under a microscope. After ipsilateral decompression, the microscope was angled medially, and the patient was tilted contralaterally to provide better visualisation of the contralateral side. After the bone and soft tissue anatomy of the contralateral side was exposed, the base of the spinous process and ligamentum flavum were resected from cephalad to caudal and from medial to lateral. The ipsilateral and contralateral nerve roots were visualised after decompression. The presence of adequate decompression was determined by observing pulsation of the dura, mobility of the nerve roots with a nerve hook, and a final fluoroscopic recheck.

After the effects of the spinal anaesthesia subsided, all patients were allowed to walk using a soft lumbar brace, which was removed 4 weeks later.

\section{Statistical Analysis}

Statistical analysis was performed using Wilcoxon signedrank and Mann-Whitney $U$ tests executed in SPSS 18.0 for Windows. A $p$ value of $<0.05$ was considered statistically significant.

\section{RESULTS}

Of the 41 patients, $23(56 \%)$ were women and $18(44 \%)$ were men, with a mean age of $79.3 \pm 2.5$ years. The average number of co-morbidities per patient was $2.01 \pm 0.5$. The co-morbidity types and their prevalence are summarized in Table I. All 34 patients presented with grade 1 spondylolisthesis, which was located at L3-4 in 10 patients, at L4-5 in 17 patients, and at L5-S1 in 16 patients (2 patients had two levels spondylolisthesis). The mean preoperative slippage rate was $18 \%$; sagittal motion was not detected on the preoperative dynamic $\mathrm{x}$-rays in any patient.

The mean surgical time was $43 \pm 4.7$ minutes, and the mean blood loss was $85 \mathrm{~mL}$. No patient received a red cell unit transfusion during hospitalization; the mean hospital stay was $2.4 \pm 0.5$ days. Patients were permitted to get up after the effects of spinal anaesthesia subsided.

The mean VAS-L scores decreased from $8.1 \pm 0.66$ at initial presentation to $4.0 \pm 1.1$ at the last visit $(p<0.01)$ postoperatively, while the mean VAS-B scores decreased from a preoperative score of $5.6 \pm 0.5$ to $3.3 \pm 0.4$ at the last visit $(p<0.05)$. The ODI scores decreased from $52 \pm 4.1 \%$ upon initial presentation to $39 \pm 3.5 \%$ at the last visit $(p<0.05)$. The mean follow-up period was 27 months (median=22 months).

In this series, no major complications were observed. Five dural tears occurred and were repaired using fibrin glue and primary sutures. Eight vesical globe cases caused by spinal anaesthesia were resolved after urinary catheter placement. No patients had subsequent operations or delayed operative fusions at the latest follow-up.

\section{DISCUSSION}

The most common cause of neurogenic claudication, back pain and radiculopathy is spinal stenosis, which can result from LDS (24). Surgical intervention is recommended for elderly patients with LDSS who do not benefit from conservative treatments (25). However, the recommended surgical procedure is still controversial topic in these patients. The nature of the clinical condition, co-morbidities, and activities of each patient are important in the evaluation of potential treatment options

Table I: Prevalence of Co-Morbidities in This Series

\begin{tabular}{lc}
\hline Co-morbidities & Percent of Patients \\
\hline Heart Disease & $24 \%$ \\
\hline Peripheral Vascular Disease & $7 \%$ \\
\hline Pulmonary Disease & $19 \%$ \\
\hline Gastrointestinal Disease & $14 \%$ \\
\hline Diabetes Mellitus & $56 \%$ \\
\hline Osteoarthritis & $65 \%$ \\
\hline Hypertension & $36 \%$ \\
\hline History of Cerebrovascular Disease & $2 \%$ \\
\hline
\end{tabular}



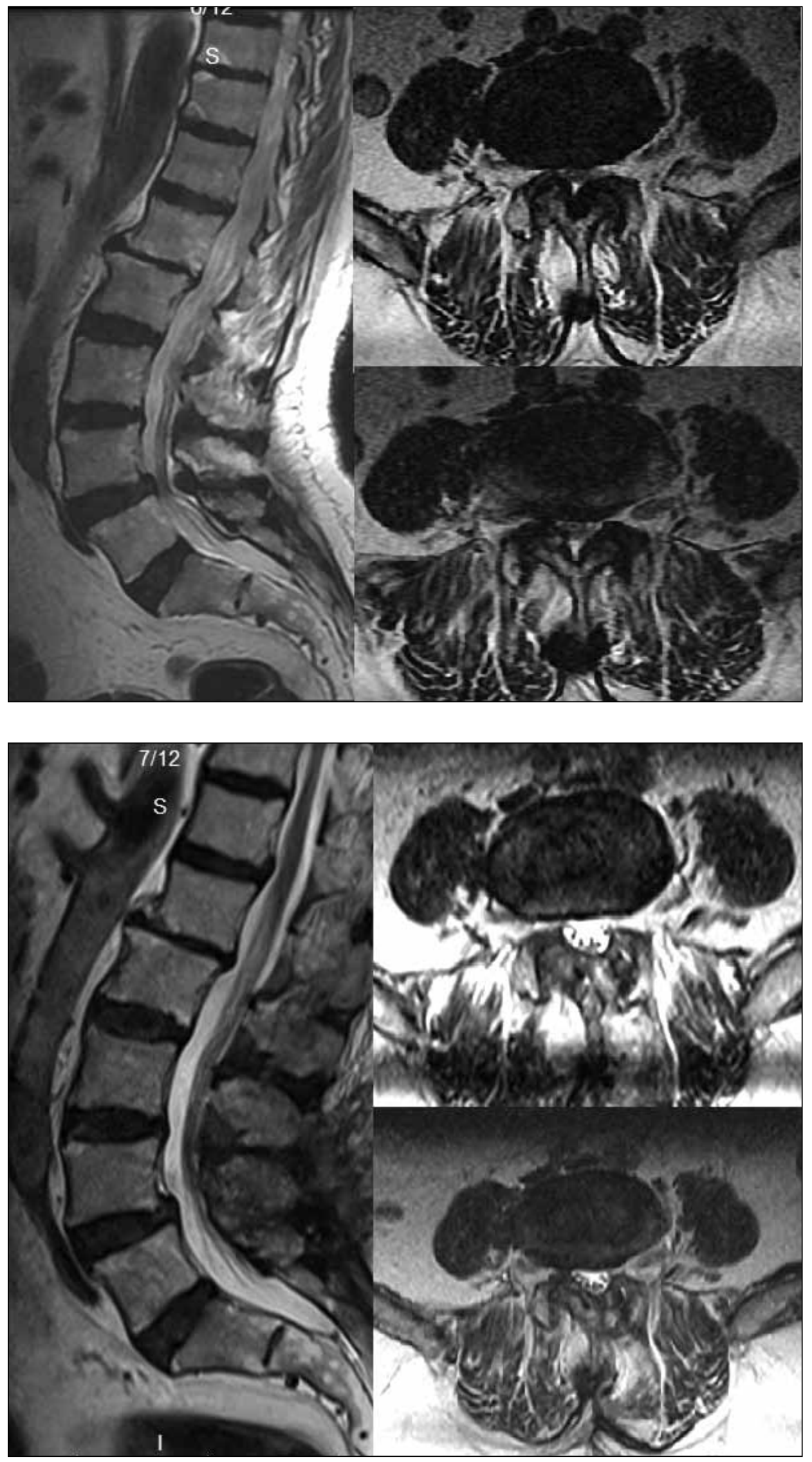

Figure 1: Pre-operative T2-weighted sagittal and axial MRI shows grade 1 sponydylolisthesis with severe stenosis.
Figure 2: Postoperative MRI image shows adequate decompression. 
(12). Surgical decompression of the spinal canal with or without fusion has been the intervention of choice for the treatment of LDSS (12). Laminectomy is one treatment option for such patients. However, this technique may contribute to subsequent lumbar instability due to extensive resection of muscle, ligament, and bone $(6,7,19)$.

Although lumbar spinal fusion surgery is recommended for the surgical treatment of LDSS based on clinical studies, complications are common in patients older than 75 years of age (5). Carreon et al. reported on their surgical complication rates after lumbar arthrodesis: at least one major and at least one minor complication occurred in $21 \%$ and $70 \%$ of elderly patients, respectively (2). In a study of patients older than 75 years of age with degenerative spondylolisthesis, 53 underwent successful fusion surgery using transpedicular screws and rods (3). Although no mortality occurred, the complication rate was $52.8 \%$; the medical and post-operative complication rate was $35.8 \%$. Such patients present with multiple co-morbidities, and spinal disease should be treated with the least aggressive surgical procedure.

Minimally invasive approaches are available as a surgical option for LDSS; these approaches preserve the posterior elements and paraspinal muscles. In addition, less blood loss occurs, shorter operative times are required, and the procedures can be performed under spinal anaesthesia (3).

In a previous study, BDUA was successful in two groups of patients with degenerative lumbar spinal stenosis and lowgrade degenerative spondylolisthesis; no patients required further surgeries. However, the mean patient age was less than 70 years in their series. This report did not include postoperative medical complications (23). The most important factors that increase the rate of medical complications are general anaesthesia and length of the surgery. It is accepted that decreased surgical time, less blood loss, and avoidance of general anaesthesia reduce the rate of complications (3).

In our series, all procedures were performed under spinal anaesthesia. The VAS-B, VAS-L, and ODI scores were satisfactory and similar to those reported in the literature, and our medical complication rate was lower. We believe that this was due to the use of spinal anaesthesia.

\section{CONCLUSION}

The results of the present study lead us to recommend the use of BDUA under spinal anaesthesia in patients over the age of 75 years with degenerative spondylolisthesis.

\section{- REFERENCES}

1. An MOR: The meaning and measurement of pain. Practitioner 160: 136-144, 1948.

2. Carreon LY, Puno RM, Dimar JR 2nd, Glassman SD, Johnson JR: Perioperative complications of posterior lumbar decompression and arthrodesis in older adults. J Bone Joint Surg Am 85: 2089-2092, 2003.
3. Costa F, Ortolina A, Tomei M, Cardia A, Zekay E, Fornari M: Instrumented fusion surgery in elderly patients (over 75 years old): Clinical and radiological results in a series of 53 patients. Eur Spine J 6: 910-913, 2013

4. Fessler RG, Khoo LT: Minimally invasive cervical microendoscopic foraminotomy: An initial clinical experience. Neurosurgery 51: 37-45, 2002

5. Futatsuki T, Kakihana Y, Nakamura K, Hirakawa A, Yamaguchi $\mathrm{K}$, Yasuda T: Spinal instrumentation and spinal fusion surgery. Masui 63: 522-527, 2014

6. Ghogawala Z, Dziura J, Butler WE, Dai F, Terrin N, Magge SN, Coumans JV, Harrington JF, Amin-Hanjani S, Schwartz JS, Sonntag VK, Barker FG 2nd, Benzel EC: Laminectomy plus fusion versus laminectomy alone for lumbar spondylolisthesis. N Engl J Med 374:1424-1433, 2016

7. Haher TR, O'Brien M, Dryer JW, Nucci R, Zipnick R, Leone DJ: The role of the lumbar facet joints in spinal stability. Identification of alternative paths of loading. Spine 19: 26672670, 1994

8. Isaacs RE, Podichetty VK, Santiago $P$, Sandhu FA, Spears J, Kelly K, Rice L, Fessler RG: Minimally invasive microendoscopy assisted transforaminal lumbar interbody fusion with instrumentation. J Neurosurg Spine 3:98-105, 2005

9. Junghanns H: Spondylolisthesis ohne Spalt im Zwischengelenkstück. Arch Orthop Unfall 29:118-127, 1930

10. Khoo LT, Fessler RG: Microendoscopic decompressive laminotomy for the treatment of lumbar stenosis. Neurosurgery 51: 146-154, 2002

11. Le H, Sandhu FA, Fessler RG: Clinical outcomes after minimal-access surgery for recurrent lumbar disc herniation. Neurosurg Focus 15: 12, 2003

12. Matsunaga S, Sakou T, Morizono Y, Masuda A, Demirtas AM: Natural history of degenerative spondylolisthesis. Pathogenesis and natural course of slippage. Spine 15: 12041210, 1990

13. McCulloch JA, Young PA: Essentials of Spinal Microsurgery. Philadelphia, PA: Lippincott-Raven, 1998

14. Monticone M, Baiardi P, Ferrari S, Foti C, Mugnai R, Pillastrini P, Rocca B, Vanti C: Development of the Italian version of the Oswestry Disability Index (ODI-I): A cross-cultural adaptation, reliability, and validity study. Spine 34: 2090-2095, 2009

15. Musluman AM, Cansever T, Yılmaz A, Cavusoglu H, Yuce I, Aydın Y: Midterm outcome after a microsurgical unilateral approach for bilateral decompression of lumbar degenerative spondylolisthesis. J Neurosurg Spine 16: 68-76, 2012

16. Oertel MF, Ryang YM, Korinth MC, Gilsbach JM, Rohde V: Long term results of microsurgical treatment of lumbar spinal stenosis by unilateral laminotomy for bilateral decompression. Neurosurgery 59: 1264-1269, 2006

17. Palmer S, Davison L: Minimally invasive surgical treatment of lumbar spinal stenosis: Two-year follow-up in 54 patients. Surg Neurol Int 3: 41, 2012

18. Perez-Cruet MJ, Kim BS, Sandhu F, Samartzis D, Fessler RG: Thoracic microendoscopic discectomy. J Neurosurg Spine 1: 58-63, 2004 
19. Postacchini F: Surgical management of lumbar spinal stenosis. Spine 24:1043-1047, 1999.

20. Rahman M, Summers LE, Richter B, Mimran RI, Jacob RP: Comparison of techniques for decompressive lumbar laminectomy: The minimally invasive versus the "classic" open approach. Minim Invasive Neurosurg 51: 100-105, 2008

21. Rosen DS, O'Toole JE, Eichholz KM, Hrubes M, Huo D, Sandhu FA, Fessler RG: Minimally invasive lumbar spinal decompression in the elderly: Outcomes of 50 patients aged 75 years and older. Neurosurgery 60: 503-509, 2007

22. Sandhu FA, Santiago P, Fessler RG, Palmer S: Minimally invasive surgical treatment of lumbar synovial cysts. Neurosurgery 54: 107-111, 2004

23. Sasai K, Umeda M, Maruyama T, Wakabayashi E, lida H: Microsurgical bilateral decompression via a unilateral approach for lumbar spinal canal stenosis including degenerative spondylolisthesis. J Neurosurg Spine 9: 554-559, 2008
24. Visser LH, Nijssen PG, Tijssen CC, van Middendorp JJ, Schieving J: Sciatica-like symptoms and the sacroiliac joint: Clinical features and differential diagnosis. Eur Spine J 22: 1657-1664, 2013

25. Weinstein JN, Tosteson TD, Lurie JD, Tosteson AN, Blood E, Hanscom B, Herkowitz H, Cammisa F, Albert T, Boden $\mathrm{SD}$, Hilibrand $\mathrm{A}$, Goldberg $\mathrm{H}$, Berven $\mathrm{S}$, An H; SPORT Investigators: Surgical versus nonsurgical therapy for lumbar spinal stenosis. N Engl J Med 358: 794-810, 2008

26. Yaman O, Ozdemir N, Dagli AT, Acar E, Dalbayrak S, Temiz C: A comparison of bilateral decompression via unilateral approach and classic laminectomy in patients with lumbar spinal stenosis: A retrospective clinical study. Turk Neurosurg 25: 239-245, 2015 